\title{
- Expression of Estrogen and Progesterone Receptors in Ovarian Neoplasms
}

IJCRR
Section: Healthcare
ISI Impact Factor
$(2019-20): 1.628$
IC Value (2019): 90.81
SJIF (2020) = 7.893
CC) (9)

\section{Faizah $^{1 *}$, Aziz Mir Rizwan², Sharma Uma ${ }^{3}$}

'Post Graduate Resident 3rd year, Department of Pathology, Faculty of Medicine and Health Sciences, SGT University, Gurugram, Haryana, India; 'Assistant Professor, Department of Radiodiagnosis, Faculty of Medicine and Health Sciences, SGT University, Gurugram, Haryana, India.; 3Professor \& Head, Department of Pathology, Faculty of Medicine and Health Sciences, SGT University, Gurugram, India.

\section{ABSTRACT}

Introduction: Ovarian cancer is one of the most aggressive malignancies of the female reproductive system and is the seventh most common cause of cancer-related deaths in females constituting about $4.0 \%$ of all female malignancies. Among cancers of the female genital tract, the incidence of ovarian cancer rank below only carcinoma of the cervix and the endometrium.

Aim of the Study: The study aims to analyze the expression of estrogen receptor (ER) and progesterone receptor (PR) immunohistochemical markers in ovarian neoplasms and correlate these with age, histological type and grade of the tumour.

Material and Methods: A retro-prospective study was conducted in the Pathology department of our institution for a period of 1 year, from April 2019 to March 2020. 57 cases of ovarian tumours were studied. Haematoxylin \& Eosin staining was done followed by immunohistochemical staining for ER and PR.

Results: Most of the tumours were benign and serous tumours were the most common histopathological entity. Expression of ER was more in malignant tumours $(76.92 \%)$ than borderline $(66.66 \%)$ and benign tumours $(53.65 \%)$. The expression of PR was more in benign $(60.97 \%)$ than borderline $(33.33 \%)$ and malignant $(38.41 \%)$ tumours.

Conclusion: ER expression was more in malignant tumours and PR expression was a more prevalent feature of benign tumours. This may support the role of estrogen in oncogenesis and indicate a protective role of progesterone in the development of ovarian carcinomas.

Key Words: Estrogen, Neoplasm, Ovarian, Progesterone, Reproductive system, IHC

\section{INTRODUCTION}

Ovarian tumours can arise from surface epithelium, germ cells, sex cord and ovarian stroma and have a diverse spectrum of histological features according to the particular tumour entity. ${ }^{1,2}$ The World Health Organization (WHO) Classification for ovarian tumours is based on the tissue of origin: surface epithelial $(65 \%)$, germ cell $(15 \%)$, sex cord-stromal $(10 \%)$, metastatic $(5 \%)$ and miscellaneous. ${ }^{3}$ Surface epithelial tumours are further sub-classified by cell type (serous, mucinous, endometrioid, clear cell carcinoma and Brenner's) and atypia (benign, borderline or malignant). Most malignant ovarian tumours are surface epithelial (90\%). ${ }^{1,2}$ About $80 \%$ of ovarian tumours are benign, and these occur mostly in young women between 20 and 35 years whereas borderline tumours occur at a slightly older age. ${ }^{3,4}$ Risk factors in ovarian carcinogenesis are not well defined. Pregnancy and oral contraceptives reduce, whereas family history increases the risk.

Steroid hormones, primarily estrogen and progesterone have been implicated in ovarian carcinogenesis. ${ }^{5}$ Estrogen favours neoplastic transformation of ovarian surface epithelial cells, whereas progesterone offers protection against ovarian cancer development.

As a higher expression of estrogen receptor (ER) and progesterone receptor (PR) has been reported in ovarian neoplasm, it is hypothesized that expression patterns of ER and PR may be related to tumour behaviour, prognosis, or both. ${ }^{6,7}$

Ovarian neoplasms are characterized by changes in the receptor status; they may be primarily receptor-negative or may have lost receptors during disease progression.

\section{Corresponding Author:}

Dr. Mir Rizwan Aziz, Assistant Professor, Department of Radiodiagnosis, Faculty of Medicine and Health Sciences SGT University, Gurugram, Haryana, India; Phone: +919315567504; E-mail: rizwan.gmc@gmail.com

ISSN: 2231-2196 (Print) ISSN: 0975-5241 (Online)

Received: $30.03 .2021 \quad$ Revised: 12.04 .2021

Accepted: 09.06 .2021

Published: 20.11 .2021 
Previous studies show estrogen receptors increased positivity in high grade / malignant tumours and progesterone receptors more in low-grade tumours. In patients with carcinoma of the breast and endometrium, the relationship between tumour estrogen and progesterone receptor (PR) levels and the prognosis is well documented. ${ }^{8}$ The clinical significance of ER and PR expression in ovarian carcinomas has not been well established in the literature. There are more studies on surface epithelial tumours, as being commonest, than compared to other ovarian neoplasms. ${ }^{9}$ Clinical significance of ER and PR expression in ovarian carcinoma has not been well established. ${ }^{8}$

\section{MATERIAL AND METHODS}

The study is based on 57 cases of ovarian neoplasm, including benign, borderline and malignant tumours, received in the Department of Pathology of our institution. This is a prospective and retrospective study after clearance from the ethical committee.

Relevant clinical details were obtained from patients' records including age, marital status, parity and presenting complaints. All specimens were thoroughly examined for size, laterality, the surface extension of tumour, unilocular/ multilocular, cystic/solid or both, microscopic subtypes and grade of the tumour.

Haematoxylin \& Eosin staining was done on paraffin sections of ovarian specimens received in the department. Immunohistochemical staining for ER and PR was done as per the standard procedure.

\section{STATISTICAL ANALYSIS}

Statistical analysis was done with Microsoft Excel 2007 software and further analyzed in SPSS version 24. All the categorical variables were expressed in terms of number/ frequency and percentages. Bar and pie charts were used to describe the categorical variables. A p-value less than 0.05 was considered statistically significant.

\section{RESULTS}

The overall mean age of the patients was $40.5 \pm 15.4$ years with the mean age in the malignant group being higher (51.27 \pm 16.05 years) than the rest. About two-thirds of the patients in this study were of the premenopausal category. Overall, the most common complaint was pain abdomen and abdominal distension. A family history of ovarian or other malignancies was seen more in the malignant group (Table 1).
On gross examination, most of the tumours were cystic comprising about $74 \%$ of the total. An overwhelming majority of these tumours were found to be benign. Only $4(7 \%)$ of the tumours were predominantly solid and all of these turned out to be malignant on histopathology. The rest of the tumours had a variegated appearance with both solid and cystic components (Chart 1).

Serous tumours were the most common histopathological entity comprising approx. $50 \%$ of the benign group as well as the overall tumours. The next common tumour was benign cystic teratoma or dermoid (24.6\%). All of these tumours were found to be benign on histopathology. Mucinous cystadenocarcinomas (15\%) and immature teratomas $(3.5 \%)$, two cases each, were noted in the malignant category.

In the current study, the expression of ER was more in malignant tumours $(76.92 \%)$ than borderline $(66.66 \%)$ and benign tumours $(53.65 \%)$ (Table 3, Chart 2). This may support the role of estrogen in oncogenesis.

The expression of PR was more in benign $(60.97 \%)$ than borderline $(33.33 \%)$ and malignant $(38.41 \%)$ tumours (Table 3, Chart 2). This probably indicates the protective role of progesterone in the development of ovarian carcinomas.

\section{DISCUSSION}

Ovarian cancer is the seventh most common cancer worldwide (Age-standardized mortality rate being 4.0/100,000). In India too, female cancer cases, especially ovarian cancer figures are escalating. India shows dangerous data of having the 3rd highest number of cancer cases among women after China and USA. India has the 2nd highest incidence of ovarian cancer globally. ${ }^{10}$ The present study was carried out on 57 cases of various ovarian neoplasms. Tumours were classified according to WHO classification. Age has a strong correlation to ovarian cancer risk and $80 \%$ of cases are diagnosed after 50 years of age. The age range in our study was 15 to 75 years (mean $40.5 \pm 15.4$ years) similar to some of the previous studies. ${ }^{11}$ It is observed that benign tumours occur in the younger age group while malignant ones mostly occur in the 5th and 6th decade. The peak incidence of benign ovarian tumours was in the age group of 20- 40 years. The youngest case in the present study was 15 years old girl, who had a dermoid cyst of the right ovary. In the Ganga Pilli et al. study, peak age was 3rd to 4th decade accounting for $55.7 \%$ of cases. The youngest case was 8 -month old..$^{12}$ Basu et al. reported mean age as $48.8 \pm 11.2$ years. ${ }^{13}$ Another study in India by Mondal et al. reported median age of 48 years at diagnosis and a maximum incidence of $44.3 \%$ in the age group of 41-50 years. ${ }^{14}$

Pain abdomen was the most common presenting symptom. Nausea, vomiting and ascites were seen in malignant tu- 
mours. In a study conducted by Sarkar et al. too, pain abdomen was the most common chief complaint overall. ${ }^{15}$

Studies reported that most of the cases of epithelial ovarian cancer occur after menopause in Caucasians. A multicentre case-control study also showed that $73 \%$ of epithelial ovarian cancer occurred after menopause in the United States. ${ }^{16}$ In our study we found that the prevalence of epithelial ovarian cancer was slightly higher in postmenopausal women $(54 \%)$ than in premenopausal women (46\%). This incidence is quite similar to one found in another study conducted in Chinese women. ${ }^{17}$

Family history of malignancy was elucidated from all the patients in our study and a positive family history of ovarian or other malignancies was seen more in the malignant group. Many studies have established higher ovarian cancer risk in women with a family history of ovarian cancer, breast cancer and cancers of other sites. ${ }^{18}$

On gross examination, the majority of the tumours were cystic in appearance comprising 40 cases $(70.17 \%)$. The next common category of tumours had a mixed appearance with both cystic and solid components contributing to 12 cases $(21.05 \%)$. The rest of the cases were purely solid in appearance. A similar proportion of cases was seen in a study conducted by Sarkar et al. ${ }^{15}$

Out of 57 cases, 41 cases were benign (71.92\%), 13 cases were malignant $(22.80 \%)$ and 3 cases of borderline tumours (5.26\%). Similar incidences of histopathological subtypes have been noted in many previous studies (Mondal et al., Sarkar et al. ${ }^{14,15}$ )

In the present series surface, epithelial tumours were the commonest, comprising 40 cases of 57 ovarian neoplasms. Serous type of tumours contributed to the majority i.e. 29 $(50.9 \%)$ of total tumours as well as the benign i.e. $21(51.2 \%)$ and malignant i.e. $6(46.1 \%)$ ones (Table 2$)$.

High estrogen (E2) levels, one of the risk factors for ovarian cancer development are often observed in ovarian cancer patients which increases the mobility of ovarian cancer cells by the inhibition of cell to cell adhesion resulting in metastasis. ER and PR show the effects of estrogen and progesterone on proliferation and apoptosis of ovarian cancer cells and a review of the literature shows that ER or PR positivity may be linked with metastasis of ovarian cancer. Ovarian cancers commonly show early peritoneal metastases; the peritoneal cavity is also the most common site of ovarian cancer recurrence. ${ }^{19}$

Similar to other studies, the present study also showed higher expression of ER in malignant cases than the expression of PR. Among the histological subtypes, ER expression was seen mostly in the serous tumours. The solitary cases of endometroid, Brenners's and granulosa cell tumours, respectively, also showed positive ER expression.
The PR expression was mostly a feature of benign tumours in our study with the dermoid cyst showing maximum PR positivity (78.57\%) followed by the serous subgroup.

These results of steroid hormone immunohistochemical expression were consistent with the previous studies like Naik et al. ${ }^{20}$ and Verma $\mathrm{N}$ et al..$^{21}$

\section{CONCLUSION}

In our current study with a limited sample size, we found that the ER expression was more in malignant tumours and PR expression was a more prevalent feature of benign tumours. This may support the role of estrogen in oncogenesis and indicate a protective role of progesterone in the development of ovarian carcinomas. However, this needs more extensive research with a much greater number of cases for better inference and a greater appeal.

\section{ACKNOWLEDGEMENT}

The authors wish to acknowledge the lab technicians of the Department of Pathology of the institution for their support.

\section{Source of Funding: Nil}

Conflict of Interest: The authors declare there is no conflict of interest among them.

\section{Author's Contribution:}

Faizah - Concept, study design, data analysis and manuscript preparation.

Aziz M R - Manuscript preparation and statistical analysis.

Sweta and Sharma U - Collection of data, data analysis and manuscript drafting.

\section{REFERENCES}

1. Su D, Pasalich M, Lee AH, Binns CW. Ovarian cancer risk is reduced by prolonged lactation: a case-control study in southern China. Am J Clin Nutr 2013; 97:354-9.

2. Mittal K, Soslow R, McCluggage WG. Application of immunohistochemistry to gynecologic pathology. Arch Pathol Lab Med 2008; 132:402-23.

3. Duska LR, Kohn EC. The new classifications of the ovarian, fallopian tube, and primary peritoneal cancer and their clinical implications. Ann Oncol. 2017; 28(suppl 8): viii8- viii12.

4. Sylvia MT, Kumar S, Dasari P. The expression of immunohistochemical markers estrogen receptor, progesterone receptor, Her-2-neu, p53 and Ki-67 in epithelial ovarian tumours and its correlation with clinicopathologic variables. Indian J Pathol Microbiol 2012; 55:33-7.

5. Ho SM. Estrogen, progesterone and epithelial ovarian cancer. Reprod Biol Endocrinol 2003; 1:73. 
6. Lukanova A, Kaaks R. Endogenous Hormones and Ovarian Cancer: Epidemiology and Current Hypotheses. Cancer Epidemiol Biomarkers Prev 2005; 14:98-107.

7. Yager JD. Chapter 3: Endogenous Estrogens as Carcinogens Through Metabolic Activation. J Natl Cancer Inst Monographs 2000; 2000:67-73

8. Liehr JG. Is estradiol a genotoxic mutagenic carcinogen? Endocrine reviews. 2000 Feb 1;21(1):40-54.

9. Atla B, Sarkar RN, Rasaputra M. Clinicopathological and IHC study (estrogen receptors, progesterone receptor, HER2/ NEU) in malignant ovarian tumours. Int J Res Med Sci. 2016 Apr;4(4):1068-73.

10. Hussein MJ, Salai JS. Clinical and histopathological features of ovarian cancer in Rizgary Hospital/Erbil City from 2014 to 2017. Medical Journal of Babylon. 2019;16(2):112-8.

11. Maheshwari V, Tyagi SP, Saxena K, Tyagi N, Sharma R, Aziz $\mathrm{M}$, et al. Surface epithelial tumours of the ovary. Indian J Pathol Microbiol 1994; 37:75-85.

12. Pilli GS, Suneeta KP, Dhaded AV, Yenni VV. Ovarian tumours: a study of 282 cases. J Indian Med Assoc. 2002;100(7):420-447.

13. Basu P, De P, Mandal S, Ray K, Biswas J. Study of "patterns of care of ovarian cancer patients in a specialized cancer institute in Kolkata, Eastern India. Indian J Cancer. 2009; 46:28-33.

14. Mondal SK, Bandyopadhyay R, Nag DR, Roychowdhury S, Mondal PK et al. Histologic pattern, bilaterality and clinical evaluation of 957ovarian neoplasms: A 10-year study in a tertiary hospital of eastern India. J Can Res Ther. 2011; 7:4337.
15. Sarkar M, Jha T, Das TK, Sau V, Mitra S, Roy K. Spectrum of epithelial ovarian tumours with HER2/neu expression by the carcinomas among patients admitted in a tertiary care hospital in Eastern India. Int J Med Sci Public Health 2015; 4:1388-1392

16. Moorman PG, Alberg AJ, Bandera EV, Barnholtz-Sloan J, Bondy $\mathrm{M}$, Cote $\mathrm{ML}$ et al. Reproductive factors and ovarian cancer risk in African-American women. Ann Epidemiol. 2016; 26:654-62.

17. Shen F, Chen S, Gao Y, Dai X, Chen Q. The prevalence of malignant and borderline ovarian cancer in pre-and post-menopausal Chinese women. Oncotarget. 2017 Oct 6;8(46):80589.

18. Negri E, Pelucchi C, Franceschi S, Montella M, Conti E, Dal Maso L et al. Family history of cancer and risk of ovarian cancer. Eur J Cancer 2003; 39: 505- 10.

19. Chen S, Dai X, Gao Y, Shen F, Ding J, Chen Q. The positivity of estrogen receptor and progesterone receptor may not be associated with metastasis and recurrence in epithelial ovarian cancer. Scientific Reports. 2017 Dec 5;7(1):1-7.

20. Naik PS, Deshmukh S, Khandeparkar SG, Joshi A, Babanagare $\mathrm{S}$, Potdar J, et al. Epithelial ovarian tumours: clinicopathological correlation and immunohistochemical study. J Midlife Health. 2015;6(4):178-83

21. Verma N, Kumar M, Sagar M, Babu S, Singhai A, Singh N, et al. Expression of estrogen receptor, progesterone receptor, and human epidermal growth factor receptor type $2 /$ neu in surface epithelial ovarian tumours and its clinicohistopathological correlation. Indian J Health Sci Biomed Res 2018; 11:19-24.

\section{Table 1: Patient demography}

\begin{tabular}{|c|c|c|c|}
\hline Parameters & Benign $(n=41)$ & Borderline $(\mathrm{n}=3)$ & Malignant (n=13) \\
\hline \multicolumn{4}{|l|}{ Age (years) } \\
\hline Mean & $37 \cdot 48 \pm 14.26$ & $47 \cdot 33 \pm 11.37$ & $51.27 \pm 16.05$ \\
\hline Common chief complaint & Pain abdomen $(73 \%)$ & $\begin{array}{l}\text { Palpable lump } \\
\qquad(67 \%)\end{array}$ & $\begin{array}{c}\text { Abdominal distension } \\
(38 \%)\end{array}$ \\
\hline \multicolumn{4}{|l|}{ Menstrual History } \\
\hline Pre-menopausal=n (\%) & $30(73 \%)$ & $2(67 \%)$ & $6(46 \%)$ \\
\hline Post-menopausal=n (\%) & $11(27 \%)$ & $1(33 \%)$ & $7(54 \%)$ \\
\hline \multicolumn{4}{|l|}{ Family History } \\
\hline Ovarian malignancy & $3(7 \cdot 3 \%)$ & $\mathrm{o}(0.0 \%)$ & $2(15.4 \%)$ \\
\hline Other malignancies & $4(9.7 \%)$ & $\mathrm{o}(0.0 \%)$ & $4(30.7 \%)$ \\
\hline
\end{tabular}

Table 2: Histological subtypes of tumour

\begin{tabular}{lcccc} 
Histopathology & Benign & Borderline & Malignant & Total \\
Serous & $21(51.2 \%)$ & $2(66.7 \%)$ & $6(46.1 \%)$ & $29(50.9 \%)$ \\
Mucinous & $6(14.6 \%)$ & $1(33.3 \%)$ & $2(15.4 \%)$ & $9(15.8 \%)$ \\
Endometroid & 0 & 0 & $1(7.7 \%)$ & $1(1.7 \%)$ \\
Brenners & 0 & 0 & $1(7.7 \%)$ & $1(1.7 \%)$ \\
Granulosa cell tumour & 0 & 0 & $1(7.7 \%)$ & $1(1.7 \%)$ \\
Dermoid & $14(34.1 \%)$ & 0 & 0 & $14(24.6 \%)$ \\
Immature teratoma & 0 & 0 & $2(15.4 \%)$ & $2(3.5 \%)$ \\
Total & $41(71.92 \%)$ & $3(5.26 \%)$ & $13(22.80 \%)$ & 57 \\
\hline
\end{tabular}


Table 3: Comparison of ER \&PR with histological subtypes

\begin{tabular}{|c|c|c|c|c|c|c|}
\hline \multirow[t]{3}{*}{ Histological subtypes } & \multicolumn{6}{|c|}{ Receptor status } \\
\hline & \multicolumn{3}{|c|}{ Estrogen Receptor (ER) } & \multicolumn{3}{|c|}{ Progesterone Receptor (PR) } \\
\hline & Negative & Positive & $P$ value & Negative & Positive & P value \\
\hline Serous & $8(27 \cdot 58 \%)$ & $21(72.41 \%)$ & & $14(48.27 \%)$ & $15(51.72 \%)$ & \\
\hline Mucinous & $4(44 \cdot 44 \%)$ & $5(55.55 \%)$ & & $6(66.66 \%)$ & $3(33.33 \%)$ & \\
\hline Endometroid & o & $1(100 \%)$ & & $1(100 \%)$ & o & \\
\hline Brenner & o & $1(100 \%)$ & 0.11 & $1(100 \%)$ & o & 0.22 \\
\hline Granulosa cell tumour & o & $1(100 \%)$ & & o & $1(100 \%)$ & \\
\hline Dermoid & $9(64.28 \%)$ & $5(35.71 \%)$ & & $3(21.42 \%)$ & $11(78.57 \%)$ & \\
\hline Immature teratoma & $2(100 \%)$ & o & & $1(50 \%)$ & $1(50 \%)$ & \\
\hline
\end{tabular}

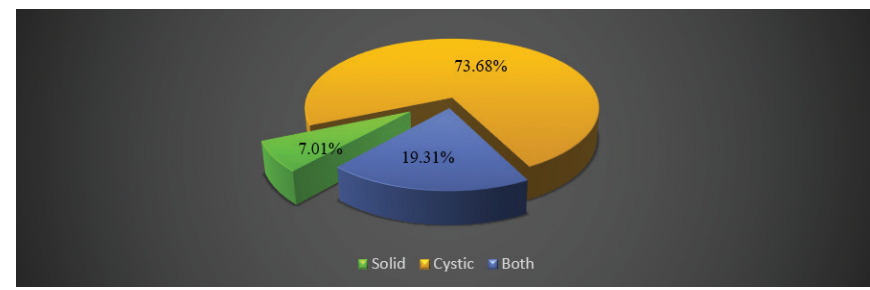

Chart 1: Gross appearance of tumours.
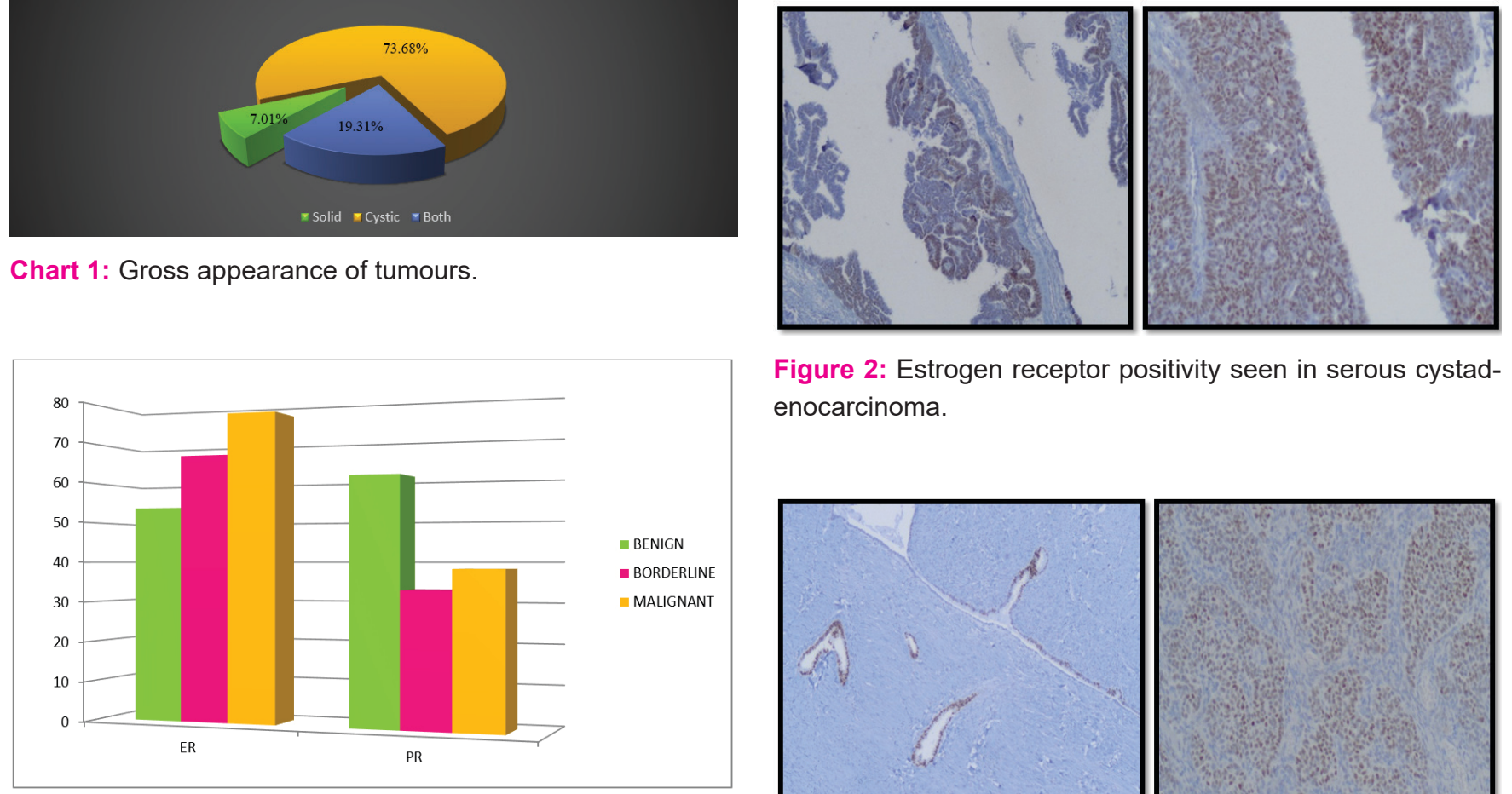

Chart 2: Expression of ER \& PR in Benign, Borderline and Malignant tumors.

Figure 2: Estrogen receptor positivity seen in serous cystadenocarcinoma.

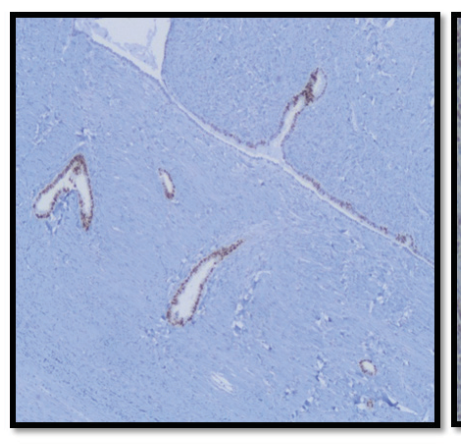

(a)

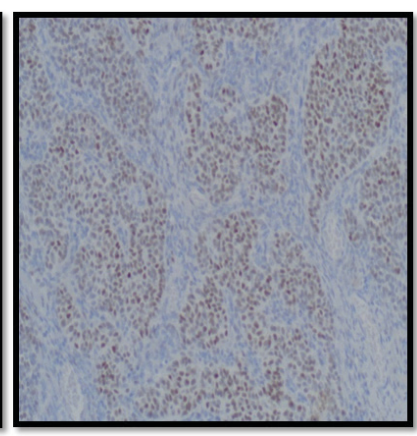

(b)

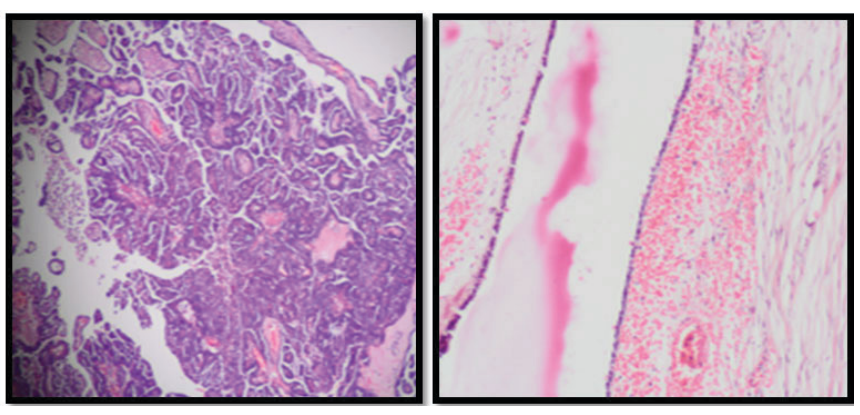

Figure 3: Progesterone receptor positivity seen in serous cystadenofibroma (3a) and granulosa cell tumor (3b).

Figure 1: $\mathrm{H}$ and $\mathrm{E}$ stained sections of papillary serous carcinoma (a) \& serous cystadenoma (b). 